\title{
CENTRO DE MEDICINA LEGAL DA FMRP-USP: RELATO DE SETE ANOS DE PRÁTICA HUMANITÁRIA COM CADÁ VERES HUMANOS NÃO-IDENTIFICADOS
}

\author{
MEDICO LEGAL CENTRE (CEMEL) OF THE FACULTY OF MEDICINE OF RIBEIRÃO PRETO-USP: \\ REPORT OF SEVEN YEARS OF HUMANITARY PRACTICE WITH UNIDENTIFIED HUMAN CORPSES
}

Carmen C. S. Martin ${ }^{1}$, Teresa C. P. Silveira², Marco A. Guimarães ${ }^{1}$, João A. D. Melki ${ }^{3}$

\begin{abstract}
${ }^{1}$ Docente. ${ }^{2}$ Técnica Especializada. Centro de Medicina Legal (CEMEL), Departamento de Patologia, Faculdade de Medicina de Ribeirão Preto -USP. ${ }^{3}$ Médico Legista do Núcleo de Perícias Médicos-Legais de Ribeirão Preto.

Correspondência: Profa ${ }^{-}$. Dra . Carmen Cinira Santos Martin. Centro de Medicina Legal (CEMEL), Departamento de Patologia, Faculdade de Medicina de Ribeirão Preto - USP. Rua Tenente Catão Roxo no 2418, Ribeirão Preto, São Paulo, CEP: 14051-140, Brasil.

Tel.: +55-16-36023360; fax: +55-16-36334476 / E-mail: ccsmart@ iof.fm.usp.br
\end{abstract}

Martin CCS, Silveira TCP, Guimarães MA, Melki JAD. Centro de Medicina Legal da Faculdade de Medicina de Ribeirão Preto - USP: relato de sete anos de prática humanitária com cadáveres humanos não-identificados. Medicina (Ribeirão Preto) 2008; 41 (1): 3-6.

RESUMO: Os autores apresentam um relato da experiência de sete anos do Centro de Medicina Legal (CEMEL) da Faculdade de Medicina de Ribeirão Preto da Universidade de São Paulo (FMRP-USP), no recebimento e guarda de cadáveres não-identificados e na atenção às famílias que procuram parentes desaparecidos. No CEMEL, vítimas de morte violenta são examinadas pelos peritos do IML, as quais podem estar carbonizadas, putrefeitas ou esqueletizadas, situações nas quais a identificação é difícil e requer atenção completa dos profissionais envolvidos. O CEMEL tem como um de seus objetivos no trabalho tanatológico, o resgate da dignidade humana no trato com os cadáveres e seus familiares, através da educação continuada de seus funcionários sobre estes princípios. De dezembro de 1999 a dezembro de 2006 foram examinados 166 cadáveres sem identificação, sendo 112 de pessoas recém falecidas, 45 esqueletizados, 7 em estado de putrefação avançada e 02 carbonizados. As entrevistas com as pessoas que se apresentaram como sendo familiares foram realizadas em todos os casos para conhecimento da história de vida do falecido, o que possibilitou a identificação de 25 pessoas. A obtenção de informações válidas para identificação foi proporcionalmente mais eficaz quanto maior o tempo de contato com os familiares, a disponibilidade em atendê-los, o interesse em ouvir suas queixas e o zêlo e trato na guarda do cadáver.

Descritores: Medicina Legal. Cadáver. Identificação de vítimas. Indigentes. Família.

\section{1- INTRODUÇÃO}

Diferentes situações históricas dificultaram a evolução da Medicina Legal no Brasil, particularmente os regimes ditatoriais ${ }^{1}$. A manutenção do exercício da Medicina Legal por longos anos, sempre da mesma maneira, distante dos centros de pesquisa, controlada por autoridades governamentais, que disponibilizavam poucos recursos para o seu crescimento e, portanto, realizada em condições precárias, tornou-a uma área desprestigiada dentro da Medicina brasileira.

O Centro de Medicina Legal (CEMEL) da Faculdade de Medicina de Ribeirão Preto da Universidade de São Paulo (FMRP-USP) foi criado através de acordo de cooperação técnico-científica entre o Instituto Médico-Legal (IML) e a Universidade de São 
Paulo (USP), como proposta alternativa ao tradicional modelo Médico Legal no Brasil.

O CEMEL tem como finalidade melhorar a assistência em Medicina Legal, desenvolver pesquisa e aprimorar o ensino acadêmico, oferecendo condições adequadas para o trabalho pericial, civil e criminal, de boa qualidade. Neste centro são examinadas, pelo IML, vítimas de morte violenta, de ocorrência recente ou não, encontradas em bom estado de conservação ou em putrefação avançada, esqueletizadas ou carbonizadas, cuja identificação é difícil e dispendiosa, exigindo adoção de política específica voltada para essa finalidade. Os diversos profissionais que nele atuam têm como objetivo comum a melhoria da qualidade do atendimento Médico-Legal às pessoas que passam por um momento extremamente delicado quando buscam um ente querido desaparecido e constatam a sua morte. Nas ações que realizam, têm como prioridade, o resgate da dignidade humana no trato com o cadáver, que em muitos necrotérios do Brasil, ocorre de forma inadequada, como frequentemente é denunciado pela imprensa.

\section{2- METODOLOGIA}

Este relato foi organizado através da análise dos registros de casos de pessoas não-identificadas que deram entrada no CEMEL de dezembro de 1999 a dezembro de 2006.

1- Após o exame pericial para esclarecimento da causa médica e jurídica da morte, o corpo era liberado para sepultamento. Nesse momento o trabalho de registro de desconhecidos iniciava-se utilizando uma ficha para o registro de informações sobre pessoas falecidas (Figura 1).

Nesta ficha passaram a ser registradas, de forma sistematizada, as informações úteis (fotografia, sinais particulares, vestimentas, objetos pessoais) para direcionar posteriormente a identificação médico-legal através de descrição e fotografia, de próteses ou órteses, das impressões digitais, do exame odontológico ou ainda, do exame de DNA. Todas as fichas foram organizadas em um livro, sistematicamente consultado para busca de pessoas desaparecidas quando familiares ou conhecidos procuravam o serviço.

2- Foram também realizadas entrevistas com prováveis familiares e conhecidos para conhecimento da história de vida do falecido em todos os casos em que houve presença dessas pessoas.

\section{3- RESULTADOS E DISCUSSÃO}

No intervalo de dezembro de 1999 a dezembro de 2006 foram registrados 166 corpos de pessoas sem identificação, sendo 112 recém-falecidas, 45 esqueletizadas, 07 em estado de putrefação e 02 carbonizados. Em todos os casos foi realizado o exame pericial necroscópico, conforme regulamentação legal.

A ficha mostrada na figura 1 foi utilizada para apresentação de dados e imagens aos interessados que buscavam pessoas desaparecidas. Este método viabilizou a identificação de 25 indivíduos.

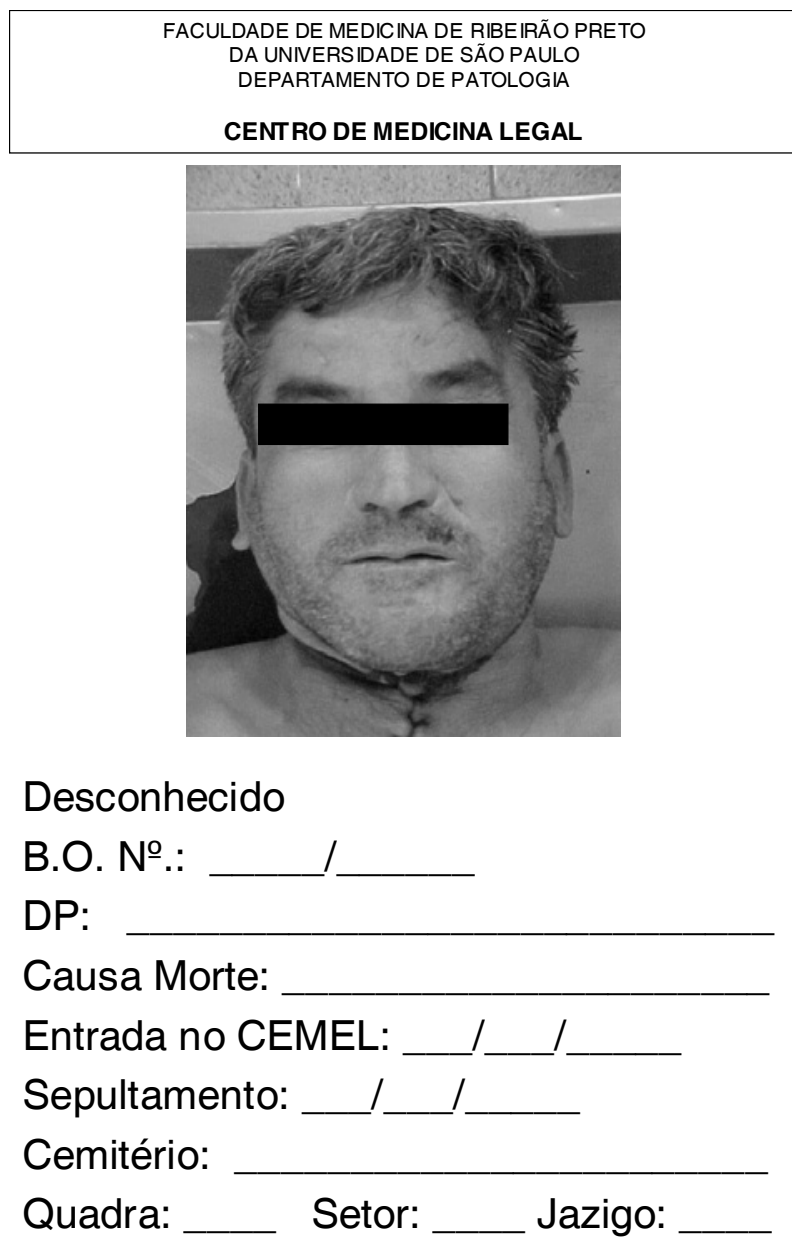

Rua Tenente Catão Roxo, 2418 -Ribeirão Preto /SP -Brasil - CEP:14051-140 Fone (16) 3602-3360 - Fax (16)3633-4476

Figura 1: Exemplo de ficha do protocolo para registro de dados úteis para reconhecimento e identificação de desconhecidos. Como pode ser observado, são registrados dados como Boletim de Ocorrência, Distrito Policial, causa morte, entrada e saída do CEMEL, informações sobre o sepultamento (quadra, setor e jazigo) que são de importância para facilitar o processo de reconhecimento e potencial identificação. 
Os corpos bem preservados, não reclamados até o $15^{\circ}$ dia, tinham suas informações divulgadas na imprensa local, seguindo a legislação ${ }^{2}$. Após esta divulgação a Declaração de Óbito era registrada em cartório com vistas ao sepultamento, de forma a evitar que os corpos entrassem em putrefação avançada, apesar da conservação em refrigerador apropriado. As informações disponíveis nas fichas foram mantidas no arquivo do CEMEL e permanecem à disposição para possíveis interessados. Quando necessário, o embalsamamento foi realizado para prolongamento do tempo de espera até que ocorresse a identificação, antes de serem enviados para sepultamento.

Os corpos de pessoas em estado de putrefação foram sepultados logo após a realização do exame necroscópico, até o ano de 2005. A partir de 2006 com a instalação do Laboratório de Antropologia Forense os mesmos passaram a ser reduzidos (retirada de restos de tecidos moles e desmembramento) e deixados na forma de esqueleto, para serem submetidos a exame antropológico. Este exame permite a obtenção de dados como sexo, faixa etária, estatura, destreza manual, particularidades do indivíduo, entre outros, que podem ser reconhecidos por familiares e desencadear a identificação.

Dos 166 corpos mencionados, $25(15,06 \%)$ nãoidentificados foram transferidos para diferentes escolas de Medicina de Ribeirão Preto, com finalidades de ensino e pesquisa, após cumpridas as exigências legais pertinentes ${ }^{2}$. Seus registros foram mantidos nos arquivos do CEMEL e permitem ainda que sejam buscados, no caso do surgimento tardio de familiares ou conhecidos.

Permaneceram sob guarda do serviço todos os esqueletos cuja identificação não foi alcançada, aguardando a possibilidade de identificação futura quando surgirem potenciais interessados.

O contato com familiares, amigos ou vizinhos, para obtenção de informações sobre pessoas falecidas, ocorreu de forma variável, em diversas entrevistas. Isso viabilizou o reconhecimento em diversos casos potencializando a identificação posterior. Contudo, deve-se lembrar que o reconhecimento é um processo subjetivo, suscetível a erros, de caráter intencional ou não, que deve sempre ser seguido de um processo científico de identificação.

Diferente do reconhecimento, a identificação é um processo científico, comparativo, objetivo, baseado em um conjunto de características biológicas individuais, que não possibilita erros por subjetividade. Sem o fornecimento de informações objetivas prévias por parte de familiares ou conhecidos, como o fornecimento de documento com impressão digital, prontuário médico ou odontológico, entre outros, o processo pode ser dificultado ou mesmo impossibilitado.

A maior dificuldade encontrada para identificar pessoas na região de Ribeirão Preto foi relacionada às características peculiares desta região como pólo de atração de imigrantes para o trabalho rural ${ }^{3}$, que chegam sem seus parentes, o que dificultou em muitos casos a obtenção de informações sobre a história de vida da pessoa falecida para o reconhecimento, assim como a ausência de documentos ou registros que viabilizassem o processo de identificação.

Contudo, notou-se que quanto maior o contato e a empatia no trato com possíveis familiares e conhecidos de uma pessoa falecida não-identificada, maiores foram as chances de um resultado positivo na identificação. Isto demonstrou que a atenção no atendimento a familiares, vizinhos ou amigos de pessoas falecidas traz benefícios relacionados à minimização do tempo de expectativa pela identificação da pessoa morta. Soma-se a isto ainda o benefício da família ter acesso aos seus direitos sociais e legais relacionados à perda do indivíduo. A postura humanitária de respeito tanto à pessoa morta como aos seus conhecidos e familiares parece ser a chave da melhoria das chances de identificação de cadáveres.

\section{4- CONCLUSÕES}

A promoção da humanização no atendimento às pessoas que procuram indivíduos desaparecidos ocorreu através da educação continuada e treinamento dos funcionários do serviço para o desenvolvimento da visão do corpo morto como sendo uma pessoa com história própria e individualidade.

O corpo morto, quando considerado como uma irradiação da personalidade em relação à sua integridade física e honra, leva à conscientização da necessidade de respeitá-lo e conhecer qual a repercussão de dano moral ou material que, porventura, possa ser provocado em seus familiares em decorrência de atendimento inadequado. Os aprimoramentos nos procedimentos de guarda de cadáveres, restos cadavéricos e coleta de material biológico útil para a identificação, demonstram que há respeito à dignidade da pessoa morta.

Para alcançar esta meta, os profissionais responsáveis pelo atendimento às famílias foram treinados para exercer a tolerância, respeitar o luto e a ne- 
cessidade de privacidade e sigilo sobre a história de vida da pessoa morta, principalmente se a mesma se encontrava desaparecida ou nos casos em que o corpo é encontrado desfigurado.

Esta conduta tem sido focalizada não apenas no momento em que a pessoa deixa de existir, mas também no encerramento de sua história de vida. A discussão sobre a doutrina da natureza do corpo como coisa ou pessoa é reiteradamente promovida entre os profissionais que lidam com familiares em luto, para conscientização da necessidade de respeitar estes últimos na fase de perda e dor.

Martin CCS; Silveira TCP; Guimarães MA; Melki JAD. Medico Legal Centre of the Faculty of Medicine of Ribeirão Preto-USP: report of seven years of humanitary practice with unidentified human corpses. Medicina (Ribeirão Preto) 2008; 41 (1): 3-6.

ABSTRACT: The authors present a report of the seven years experience of the Medico Legal Centre (CEMEL) of the Faculty of Medicine of Ribeirão Preto of the University of São Paulo (FMRPUSP) in receiving and keeping non-identified copses and in the attention to the families that search for missing relatives. In CEMEL, victims of natural, suspicious or violent deaths are examined, whose can be carbonized, putrefied or skeletonized, situations in which identification is difficult and require full attention of professionals involved. CEMEL has as priority the rescue of human dignity in dealing with corpses and their families, because of the repetitive denounces of disrespectful treatment in many mortuaries in Brazil. From December 1999 to December 2006, 166 non-identified bodies were examined, being 112 of recent deaths, 45 skeletonized, 7 in advanced putrefaction and 2 carbonized. The interviews with those allegedly relatives was done in all cases to obtain the life history of the deceased, which allowed the identification of 25 people. Obtaining valid information for identification was proportionally more efficient to the longer time spent with the relatives, the availability in help, the interest in listening to their complaints and the care in keeping the corpses.

Keywords: Forensic Medicine. Cadaver. Victims identification. Homeless people. Family.

\section{REFERÊNCIAS}

1 - Guimarães, MA. The challenge of identifying deceased individuals in Brazil: from dictatorship to DNA analysis. Sci Justice. 2003; 43 (4): 215-17.

2 - Brasil. Lei no 8.501, de 1992. Dispõe sobre a utilização de cadáver não reclamado, para fins de estudos ou pesquisas científicas e da outras providências. Brasília, DF, 30 de novembro 1992.

3 - Adam D. Back from the dead. Nature 2003; 423: 13-4.

Recebido para publicação em 27/08/2007

Aprovado para publicação em 13/05/2008 